\title{
MAKING ROCKS SWIM
}

KNIGHT, Graham J., Department of Earth Sciences, University of Manchester, Manchester, M13 9PL, UK.

This presentation will centre around the potentials and limitations of gathering biomechanical behavioural information of animals from non-living evidence of their structure: that is, how to work out the likely locomotion of animals from exclusively fossil evidence.

A computer model, based on fundamental hydrodynamic principles, has been devised in order to predict the swimming capabilities of eurypterids, extinct arthropods of the Palaeozoic. The model is tested using morphological data from the living swimming crab Callinectes sapidus, whose swimming abilities and techniques are well-documented. The empirical optimal swimming scheme which is predicted by the model corresponds well with that demonstrated by the animal, and the deviations which do occur can be explained.

A range of eurypterids, Baltoeurypterus, Pterygotus, Salteropterus, Dolichopterus and Carcinosoma, are examined using hydrodynamic data obtained from flume tank experiments with clay reconstructions of the animals. The computer model suggests that some species of eurypterids were highly capable swimmers, with the adults employing a range of liftbased techniques and achieving speeds comparable to those of similar-sized marine mammals of the present. 